\title{
Obesity diabetes and the role of bile acids in metabolism
}

\author{
Gerald H. Tomkin, Daphne Owens \\ Diabetes Institute of Ireland Beacon Clinic Dublin and Trinity College, Dublin 2, Ireland
}

\section{ABSTRACT}

Bile acids have many activities over and above their primary function in aiding absorption of fat and fat soluble vitamins. Bile acids are synthesized from cholesterol, and thus are involved in cholesterol homeostasis. Bile acids stimulate glucagon-like peptide 1 (GLP1) production in the distal small bowel and colon, stimulating insulin secretion, and therefore, are involved in carbohydrate and fat metabolism. Bile acids through their insulin sensitising effect play a part in insulin resistance and type 2 diabetes. Bile acid metabolism is altered in obesity and diabetes. Both dietary restriction and weight loss due to bariatric surgery, alter the lipid carbohydrate and bile acid metabolism. Recent research suggests that the forkhead transcription factor FOXO is a central regulator of bile, lipid, and carbohydrate metabolism, but conflicting studies mean that our understanding of the complexity is not yet complete.

Key words: obesity, diabetes, bile, acids, bariatric surgery, FOXO

\section{INTRODUCTION}

Bile acids are instrumental in solubilising dietary fat to allow intestinal absorption. Bile acids are synthesized in the liver from cholesterol, thus bile acid synthesis is a regulator of body cholesterol. The primary bile acids are chenodeoxycholic acid and cholic acid, which become conjugated in the human liver to taurine or glycine. The conjugated bile acids have a hydrophilic and hydrophobic moiety, which enables them to solubilize fat for absorption. Only the short chain fatty acids are amenable to absorption without the aid of bile acids. The primary bile acids are actively re-absorbed in the distal ileum and recycled, but those that escape re-absorption are de-conjugated to deoxycholic acid and lithocholic acid by colonic bacteria - mostly the bacteroides species - and reabsorbed through the portal system $^{[1]}$. Ursodeoxycholic acid makes up about 3\% of the total bile acids and has anti-inflammatory properties that have been used in hepatitis and bile acid reflux conditions $^{[2]}$.

As shown in Figure 1, diversion of the biosynthetic pathway of cholesterol to bile has been utilized to lower cholesterol through up-regulation of cholesterol 7 alpha hydroxylase, the rate limiting enzyme. The bile salts are excreted by the liver into the gall bladder, an organ, the contraction of which is regulated both by hormones and the autonomic nervous system ${ }^{[3]}$.

\section{BILE ACID TOXICITY}

The toxicity of deoxycholic acid continues to interest scientists ${ }^{[4]}$. Deoxycholic acid modulates cell death through the changes in mitochondrial membrane properties. Cholestasis is associated with hepatitis and both hepatocyte and bile duct cell death through apoptosis, and in higher concentrations, by necrosis ${ }^{[5-7]}$. Deoxycholic acid is hydrophobic, but ursodeoxycholic acid, which is highly hydrophilic, inhibits apoptosis. Souswa et al. ${ }^{[4]}$ have shown that deoxycholic acid causes its apoptotic effect through disruption of the mitochondrial outer membrane an effect not caused by ursodeoxycholic acid.

Oesophageal cancer is, alas, a devastating disease. Bile acid reflux is thought to play an important part in its aetiology. 


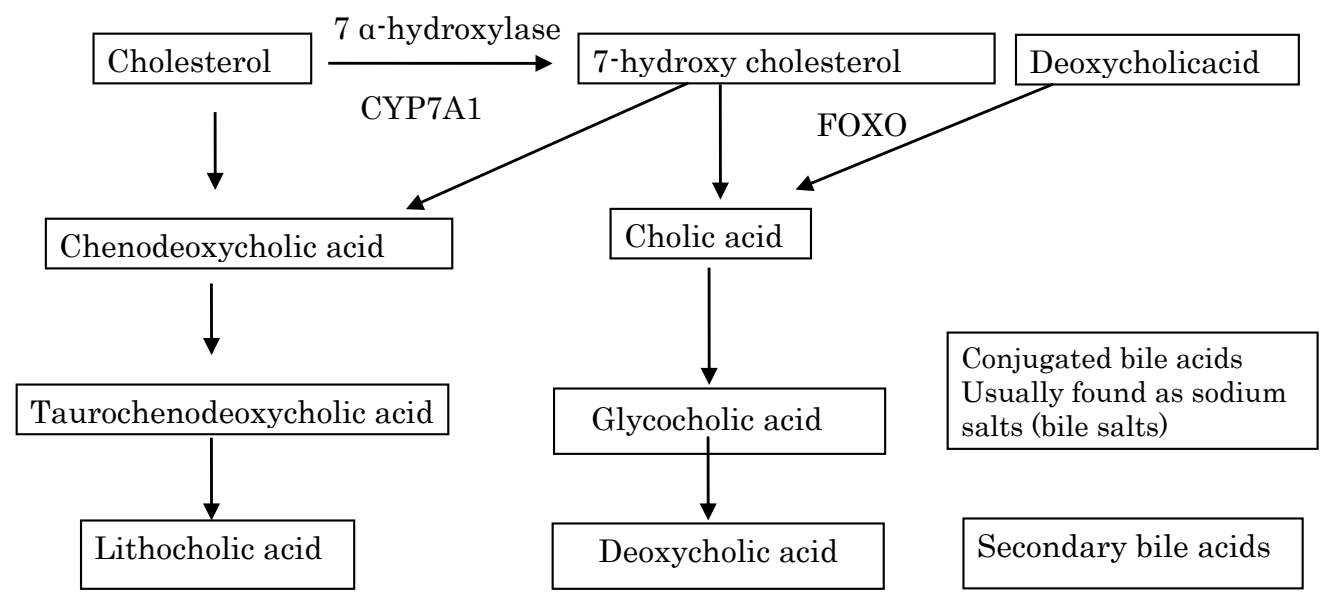

Figure 1: Bile acid metabolism

Abdel-Latif et al. ${ }^{[8]}$ have shown that ursodeoxycholic inhibits deoxycholic acid-induced signalling pathways in oesophageal cancer cells through the inhibition of deoxycholic acid's ability to induce NF-kB and activator protein-1 COX 2 promoter. The authors suggest that this pathway inhibition may possibly account for the chemopreventive actions of ursodeoxycholic acid in oesophageal carcinogenesis.

\section{BILE ACID-ACTIVATED RECEPTORS}

Bile acids have other properties. There are a number of bile acid-activated receptors, including farsinoid X receptor (FXR). Bile acid activation of FXR in the intestine stimulates synthesis of fibroblast growth factor (FGF) 15/19, which is involved in lipid and carbohydrate metabolism. FXR, through its downstream effect on FGF, is important in maintaining normolipidaemia, normoglycaemia, and bile acid homeostasis ${ }^{[9,10]}$. FGF inhibits CYP7A1 expression, the first step in the conversion of cholesterol to bile acids. Chenodeoxycholic acid for example increases LDL through this pathway ${ }^{[11]}$.

As shown in Figure 2, the $12 \alpha$-hydroxylated bile acids are particularly associated with insulin resistance. Haeusler and Astiarraga ${ }^{[12]}$ have shown in 200 non-diabetic and 35 patients with type 2 diabetes that $12 \alpha$-hydroxylated/ non-12 $\alpha$-hydroxylated bile acid ratio was associated with the key features of insulin resistance, including higher insulin, proinsulin, glucose, glucagon, and triglycerides with lower HDL cholesterol. In type 2 diabetes, bile acids were nearly two-fold elevated and more hydrophobic than healthy subjects. In a previous animal paper, Hausler et al. ${ }^{[13]}$ proposed that $12 \alpha$-hydroxylated products of bile acid metabolism represented a signalling mechanism, linking the hepatic lipid abnormalities with type 2 diabetes. They showed that a deficiency of $12 \alpha$-hydroxylated bile acids and their synthetic enzyme CYP8B1 hinder the triglyceride, lowering effects of FXR. More recently, Fang et al. ${ }^{[14]}$ have shown that the bile acid release during a meal activates intestinal FXR. Up-regulating FXR with an intestinal agonist reduced diet-induced weight gain and hepatic glucose production while enhancing thermogenesis and browning of white adipose tissue. Other bile acid receptors include constitutive androstane receptor, pregnane $\mathrm{X}$ receptor, and Vitamin D receptor (for review, see Distrutti et al. $\left.2015^{[3]}\right)$.

\section{G-PROTEIN-COUPLED RECEPTORS}

The bile acids can also activate voltage and calcium-gated potassium channels. Bile acids also interact with tyrosine kinase-coupled receptors, causing the transactivation of epidermal growth factor receptor. The secondary bile acids activate $G$-protein-coupled receptors. Each bile acid interacts with more than one receptor ${ }^{[15]}$. G-proteincoupled bile acid receptor 1 (Gp-BAR1) is expressed mostly in the intestine and is involved in motility, inhibiting both peristalsis in the colon and gastric emptying ${ }^{[16,17]}$. Katsuma et al. ${ }^{[18]}$ have shown that bile acids promote glucagon-like peptide-1 (GLP-1) secretion through the bile receptor GPBAR-1 in a murine entero-endocrine cell line. GLP1 agonists are used in the treatment of type 2 diabetes because of their insulin-stimulating effect on the pancreatic $\mathrm{B}$ Cell, the inhibition of gastric emptying and the central effect on apatite inhibition, resulting in weight loss ${ }^{[19]}$. GLP1 is secreted by $\mathrm{L}$ cells that are found in the distal ileum, colon, and rectum. Intrarectal taurocholate has been shown to increase L cells and insulin secretion ${ }^{[20]}$. The authors showed that the increase in GLP-1 was associated with an 


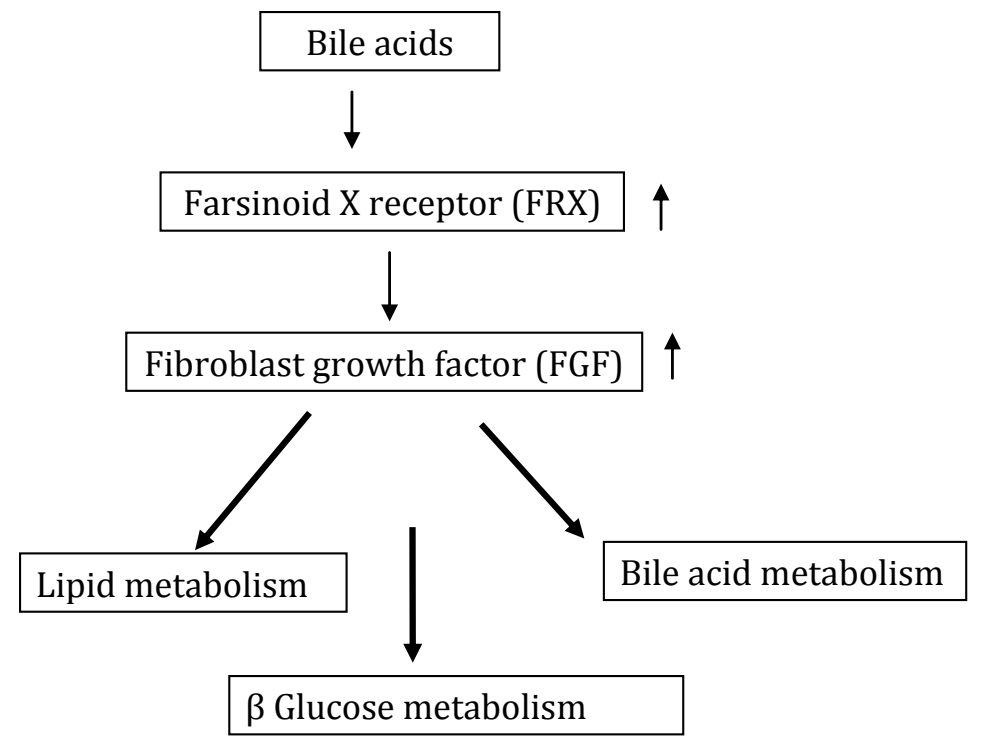

Figure 2: Effect of bile acids on glucose and lipid metabolism

increase in peptide YY (PYY) and insulin with a reduction in food intake of a previously selected favorite meal. GLP-1 is rapidly broken down by Dipeptidyl peptidase-4 (DPP4). DPP4 inhibitors have been introduced to treat diabetes. Osto et al..$^{[21]}$ have shown that in rats that Roux en Y gastric bypass down-regulates DPP-4

\section{BARIATRIC SURGERY AND TYPE 2 DIABETES}

Reversal of type 2 diabetes can occur rapidly with weight reduction ${ }^{[22]}$. Weight reduction may be achieved by calorie restriction, but for most patients an impossible dream. Bariatric surgery is an alternative with excellent results in most cases. The Roux en Y procedure is perhaps the most effective operation, but also has a potential problem in the creation of a blind loop ${ }^{[23]}$. Sleeve gastrectomy is another frequently performed operation, which does not have the disadvantage of the formation of a blind loop. However, the weight loss results are somewhat inferior at least in the short term. A recent study comparing different types of gastric bypass operations found little difference in outcome at 5 years when remission of diabetes was investigated and little difference in BMI at 5 years between gastric banding, sleeve gastrectomy, and Roux en Y operations, even though early improvements were the greatest for the Roux en Y group, but this advantage diminished with time ${ }^{[24]}$. A recent review of bariatric surgery in adolescent patients found little difference in weight reduction when Roux en $\mathrm{Y}$ was compared with sleeve gastrectomy ${ }^{[25]}$. The patients who had the Roux en Y procedure were the heaviest at the start with a mean BMI of 54 (52-55), whereas the sleeve gastrectomy subjects had a mean BMI of 50 (48-52). The percent change was 28 for the Roux en $\mathrm{Y}$ as compared to 26 for the sleeve gastrectomy operation. Comparing complications following the operations is difficult, but it seems as if sleeve gastrectomy is the safer procedure. The event rate of intra-abdominal operations for the Roux en $\mathrm{Y}$ was 38/300 person years and 15.4 for the sleeve gastrectomy operation. Sleeve gastrectomy has been shown to alter the bile acid profile and reduce primary bile acids and increase secondary bile acids ${ }^{[2]}$. An improvement in insulin resistance and diabetic control may, in part, be due to alteration of the bile acid composition with stimulation of GLP-1. Following Roux-en Y gastric bypass, total bile acids increased after 1 month due to an increase in secondary bile acids. At 24 months, there was an increase in both primary unconjugated bile acids as well as secondary deoxycholate conjugated with glycine. The authors suggest that the changes were bacterially derived ${ }^{[27]}$.

\section{EFFECT OF BILE ACIDS ON LIPID AND GLUCOSE METABOLISM}

The increase in bile acids strongly correlates with the improvement in glucose and lipid metabolism ${ }^{[28,29]}$. Interestingly, catheter-mediated bile diversion to the mid distal jejunum in rats induces weight loss, decreases adiposity, improves glucose tolerance, and increases circulating bile acids ${ }^{[30]}$. On the other hand, bile acid concentrations have been found to be increased in obese patients with type 2 diabetes ${ }^{[31]}$. Bariatric surgery was found to increase bile acids, but a hypocaloric diet, which induced similar weight loss, was associated with a reduction in the level of uncongugated bile acids ${ }^{[32]}$, suggesting that bile acid changes are not the main reason for improvement in 
glucose tolerance following gastric bypass operations. FXR activation of $\mathrm{L}$ cells in the ileum by the bile acids may be one mechanism involved in the improvement of diabetes ${ }^{[33]}$. On the other hand, microbiota convert primary bile acids into secondary bile acids, and it is the secondary bile acids that downregulate FXR most effectively ${ }^{[34]}$. This effect may, at least in part, modify the beneficial effect of bile acids on glucose and lipid metabolism in subjects who have had a Roux en Y operation and have developed an infected blind loop, and therefore, de-conjugation of bile salts higher up in the small bowel rather than in the colon ${ }^{[35]}$.

The incidence of infection in the blind loop in humans who have had Roux en Y operation has not been examined to our knowledge. The effect of Roux en Y bypass surgery on bile acid metabolism in normal and obese diabetic rats has recently been published ${ }^{[36]}$. This study was instigated following the reports that Roux en $\mathrm{Y}$ is associated with an increase in bile acids ${ }^{[37-41]}$. The authors investigated both a rat diabetic model (Zucker diabetic rat) and normoglycaemic Sprague Dawley rats. The study confirmed an increase in bile acids at day 28 post operation. No difference was found between the diabetic and non-diabetic rats. The changes, however, did not happen immediately, suggesting, according to the authors, that the early improvement in glucose metabolism was not related to the changes in bile, although there was a transient increase in fecal bile in the zucker rats, but by day 28 , the fecal increase was no longer detectable. The non-diabetic rats had decreased fecal total bile acids. The authors conclude that the study suggested that the changes in bile acids are unlikely to mediate early weight independent improvements in glucose homeostasis The study found no evidence that the increase in bile acids was due to increased hepatic synthesis, nor did they find evidence from gene expression patterns, that increased re-absorption played a part in the increased plasma bile acids. Jorgensen and Dirksen ${ }^{[42]}$ found in 13 type 2 and 12 normal glucose tolerant subjects, 1 week, 3 months, and 1 year after Roux en $\mathrm{Y}$ operation, total bile acids decreased in the normoglycaemic subjects, but were unchanged in the diabetic subjects at 1 week, but then increased in both groups with time after surgery. One week after the surgery, glucose metabolism improved as did the lipid pattern, GLP1 , and cholecystokinin. The authors concluded that the bile acids did not explain the rapid improvement in glucose and lipid metabolism or the stimulation of GLP-1. Temporal changes in bile acids and 12a-hydroxylation after Roux en Y operations have been recently reported by Dutia et al. ${ }^{[43]}$ They found that fasting bile acids were generally reduced at 1 month, but increased after 2 years, whereas postprandial bile acids were unchanged at 1 month, but there was an exaggerated peak at 2 years. The ratio of 12a-hydroxylated bile acids to non $12 \mathrm{a}$ bile acids was increased at 2 years, but not at 1 month, again suggesting that an early improvement in glucose metabolism is unrelated to the changes in bile acids.

\section{BILE ACIDS METABOLISM AND ENERGY EXPENDITURE}

It has been suggested that bile acids may be involved in regulation of food intake. Prinz et al. ${ }^{[44]}$ have shown that bile acids are negatively correlated with the cognitive restraint of eating in obese patients. The authors studied anorexia subjects who were underweight and compared them with the normal weight and obese patients who had BMI of $30-40$ or $40-50$ or $>50$. They found that bile acids had a positive correlation with BMI and a significant negative correlation with cognitive restraint of eating. In obese patients, it is possible that the mechanism might be through stimulation of GLP-1, but this was not measured in their paper. The energy expenditure has not been shown to increase after weight reduction due to hypocaloric diet with or without bariatric surgery ${ }^{[45]}$. Bile acids have, however, been shown in mice to increase energy expenditure by increasing UCP-1 expression, probably independent of adrenergic signalling ${ }^{[46,47]}$.

An interesting recent paper investigates the role of bile acids in metabolic control in obese mouse model ${ }^{[35]}$. The study examined Roux en Y gastric bypass compared to diverting bile acids to either the jejunum or ileum on weight, adiposity, glucose homeostasis, and liver metabolism. The authors also examined the effect of the bile diversion on the gut microbiota profile. The analysis was of caecal rather than small bowel microbiota and the Roux en Y group were not examined. The ileal but not the jejunal bile diversion was associated with weight loss and reduction in calorie intake similar to the Roux en Y. Pair feeding revealed that the reduced calorie intake was not the only factor in the weight reduction that occurred with either the ileal diversion or Roux en Y. The ileal diversion was associated with a nearly 10 fold increase in conjugated bile acids tauro, omega, and beta muricholic acid, the latter being a secondary bile acid with strong FXR antagonism activity ${ }^{[34]}$. The ileal diversion resulted in improved insulin sensitivity similar to the Roux en Y group. As expected, the ileal bile diversion lowered cholesterol more than Roux en Y presumably due to malabsorption, even though the basolateral and apical ileal bile acid transporters in the ileum were increased and serum bile acids were also increased and both procedures resulted in fecal fat being increased. Bile acids have been shown to increase energy expenditure through TGR5 (also called GPBAR1)-mediated processes in both skeletal muscle and adipose tissue ${ }^{[48-50]}$. After adjustment for total body mass or fat free mass both the ileal diversion mice and the Roux en $\mathrm{Y}$ mice increased energy expenditure as compared to the control and jejunal diverted bile group. 
The colonic bacteria were examined in the biliary diversion groups. Firmicutes were less represented and bacteriocides increased in the ileal diversion group, but not measured in the Roux en Y mice. Proteobacteria were also increased relative to the other two biliary diversion groups.

\section{MICROBIOTA}

The effects of surgical and dietary weight loss for obesity on gut microbiota composition and nutrient absorption have been reported recently ${ }^{[51]}$. Fecal sampling showed that the low calorie diet resulted in less changes than slieve gastrectomy, which changed the ratio of firmicutes/ bacteroidetes. The authors suggest that the changes are perhaps due to the differences in diet after the operation or very low calorie diet of the non-operated subjects. Kong et al. ${ }^{[52]}$ examined gut microbiota after Roux en Y surgery, and found increased microbiota, $37 \%$ due to proteobacteria. They also found an increase in Bacteroides. However, it has been pointed out that fecal microbiota are a poor substitute for small bowel sampling if one is interested in bacterial alterations of bile in the small bowel ${ }^{[53]}$.

The blind loop syndrome is not new having been explored when Bilroth 11 operations or gastroenterostomy with vagotomy were so frequently done to cure duodenal ulcers. The metabolic effects of bacteria in the small bowel are considerable and include the deconjugation of bile salts and the production of secondary bile acids. Many years ago, we showed the toxic effects of deoxycholic acid on rat intestinal mucosa ${ }^{[54]}$. Bacterial overgrowth is associated with Vitamin B12 deficiency, but also with an increased bile acid excretion since secondary bile acids are not actively reabsorbed in the distal ileum. Diabetic patents who have severe autonomic neuropathy may present with severe diarrhoea ${ }^{[5]}$. This may be due alteration in bile acid metabolism, causing choleric diarrhoea. We showed that these patients have an increased bile salt pool size with alteration in bile salt composition. Cholestyramine, a bile acid sequestrant, has sometimes been successful in treating the condition ${ }^{[56]}$.

\section{BILE ACIDS, STEATOHEPATITIS, AND BILOPANCREATIC DIVERSION}

Diabetes and obesity are common bed fellows, and nonalcoholic steatohepatitis (NASH) is an alarming association because of the progression to cirrhosis. It has been shown that patients with NASH have higher serum total bile acids due to both primary and also the more toxic, secondary bile acids conjugated with glycine and taurine. Exposure to these higher levels might play a part in the development of fatty liver disease and steatohepatitis ${ }^{[57]}$. It is reassuring that weight reduction clears hepatic fatty infiltration rapidly whether the weight reduction is due to surgical intervention or dietary restriction alone $e^{[22,58]}$.

Ferrinini et al. ${ }^{[59]}$ have investigated bile acid synthesis and deconjugation after bilopancreatic diversion with the thesis that this surgical intervention has the strongest effect on weight loss and the highest frequency of type 2 diabetes resolution. They studied morbidly obese and overweight diabetic patients undergoing Roux en Y operations or biliopancreatic diversion surgery. They studied the patients before the surgery, 2-10 weeks after surgery and again 1-2 years later. Insulin sensitivity improved in all three groups. In the Roux en Y group, the improvement in insulin sensitivity was in proportion to weight loss, whereas in the biliary pancreatic diversion group, the insulin sensitivity peaked earlier and did not seem to be related to weight loss. Cholesterol halved at 7 weeks in the biliary pancreatic diversion group. Plasma bile acids increased in all groups, but conjugated more than unconjugated in the Roux en Y group, whereas the pattern was the opposite in the pancreaticobiliary diversion group. The markers of bile acid synthesis were not increased in the Roux en $\mathrm{Y}$ patients, but markedly increased in the biliary pancreatic group. The study explains the LDL lowering effect of the diversion operation, but does not help to understand the improvement in insulin sensitivity. As the authors suggest, the study indicates that further studies may help to understand the impact of bariatric surgery on glucose and lipid metabolism.

\section{THE FORKHEAD BOX PROTEINS (FOXO)}

The forkhead box proteins (FOXO) have provided a link between glucose and lipid metabolism in the liver. These transcription factors (isoforms $13 \mathrm{a} 4$ and 6) have provided an explanation as to the way glucose and lipid metabolism interact and how the fuel storage system works to provide energy fasting or after a meal ${ }^{[60,61]}$. FOXO is the switch mechanism, which either promotes hepatic glucose production by stimulating glucose-6-phosphatase, the rate limiting enzyme in hepatic glycogenolysis or switches to lipid metabolism. In diabetes, a reduction in FOXO leads to a reduction in glycogenolysis and an increase in hepatic glucose output. In studies in mice, the deletion of FOXO1 and FOXO3 decreased blood glucose, elevated serum triglyceride, and cholesterol. The deletion increased hepatic lipid secretion and caused hepatosteatosis, demonstrating the powerful effect of FOXO on switching energy utilization from glucose to lipid ${ }^{[62,63]}$.

Bile acid synthesis has been shown to be controlled by FOXO. Haeusler et al..$^{[13]}$ have shown that FOXO1 deletion 
is associated with raised triglycerides and a reduction in $12 \alpha$-hydroxylated bile acids with a reduction in the gene regulating Cyp8b1, which encodes the $12 \alpha$-hydroxylase enzyme. This suggests a link between bile acid regulation and lipid and glucose metabolism. Bile acid sequestrants reduce glucose and cholesterol levels in type 2 diabetes $^{[64]}$.

Insulin resistance is associated with increased plasma levels of $12 \alpha$-hydroxylated bile acids ${ }^{[12]}$. Bile acids are increased after bariatric surgery, but not after a hypocaloric diet ${ }^{[31]}$. The exciting work by Fang et al. ${ }^{[14]}$ shows that the bile acid release during a meal selectively activates the intestinal FXR. They showed that the intestinal FXR agonist fexaramine induces FGF 15, leading to alterations in bile acid composition, reduced diet-induced weight gain, and hepatic glucose production, while enhancing thermogenesis and browning of white adipose tissue. The absence of FXR has been shown to decrease the benefit of bariatric surgery on weight loss and glucose tolerance ${ }^{[12]}$. This is in keeping with the results of bile diversion to the distal small intestine, which also results in improved weight loss, glucose tolerance, and hepatic steatosis through a 10 -fold increase in bile acids. The FGF15 expression was decreased $^{[35]}$. Gastric bypass operations reduced FOXO1 in the liver in diabetic rats but also in the pancreatic B cell, raising the possibility that this regulator in the pancreas may also be in part a cause of the improvement in glucose tolerance ${ }^{[65,66]}$.

\section{CONCLUSION}

In conclusion, the knowledge of the role of bile acids in the metabolism of cholesterol and also of triglycerides has expanded. Important recent observations now link dysregulation of bile acid metabolism to dyslipidaemia, insulin resistance, and diabetes. The discovery of the FOXOs has been important in delivering a unified mechanism to understand the metabolic dysregulation that occurs in obesity and type 2 diabetes. Bariatric surgery has stimulated a lot of research in this area since it is so effective in causing weight reduction and reversing diabetes.

\section{Conflict of Interest}

None declared.

\section{REFERENCES}

1. Russell DW. The Enzymes, Regulation, and Genetics of Bile Acid Synthesis Annual Review of Biochemistry 2003;72: 137-74.

2. Beuers U, Boyer JL, Paumgartner G. Ursodeoxycholic acid in cholestasis: Potential mechanisms of action and therapeutic applications Hepatology 1998; 1449-53.

3. Distrutti E, Santucci L, Cipriani S, Renga B, Schiaroli E, Ricci P, et al. Bile acid activated receptors are targets for regulation of integrity of gastrointestinal mucosa. J Gastroenterol 2015;50:707-19.

4. Sousa T, Castro RE, Pinto SN, Coutinho A, Lucas SD, Moreira R, et al. Deoxycholic acid modulates cell death signalling through changes in mitochondrial membrane properties. J Lipid Res 2015;56:2158-71.

5. Schmucker DL, Ohta M, Kanai S, Sato YK. Hepatic injury induced by bile salts: correlation between biochemical and morphological events. Hepatology 1990; 12:1216-21.

6. Castro RE, Amaral JD, Solá S, Kren BT, Steer CJ, Rodrigues CMP. Differential regulation of cyclin $\mathrm{D} 1$ and cell death by bile acids in primary rat hepatocytes. Am. J. Physiol. Gastrointest. Liver Physiol 2007;293:G32734.

7. Gumpricht E, Devereaux MW, Dahl RH, Sokol RJ. Glutathione status of isolated rat hepatocytes affects bile acid-induced cellular necrosis but not apoptosis. Toxicol Appl Pharmacol 2000; 164:102-11.

8. Abdel-Latif MM, Inoue H, Reynolds JV. Opposing effects of bile acids deoxycholic acid and ursodeoxycholic acid on signal transduction pathways in oesophageal cancer cells. Eur J Cancer Prev. 2015 Sep 16. [Epub ahead of print].

9. Cariou B, van Harmelen K, Duran-Sandoval D, van Dijk TH, Grefhorst A, Abdelkarim $\mathrm{M}$, et al. The farnesoid $\mathrm{X}$ receptor modulates adiposity and peripheral insulin sensitivity in mice. J Biol Chem 2006;281:1103949. Epub 2006 Jan 30.

10. Ma K, Saha PK, Chan L, Moore DD. Farnesoid X receptor is essential for normal glucose homeostasis J Clin Invest 2006;116:1102-9.

11. Porez G, Prawitt J, Gross B, Staels B. Bile acid receptors as targets for the treatment of dyslipidemia and cardiovascular disease. J Lipid Res 2012;53:1723-37.

12. Haeusler RA, Astiarraga B, Camastra S, Accili D, Ferrannini E. Human insulin resistance is associated with increased plasma levels of 12a-hydroxylated bile acids. Diabetes 2013;62:4184-91.

13. Haeusler RA, Pratt-Hyatt M, Welch CL, Klaassen CD, Accili D. Impaired generation of 12-hydroxylated bile acids links hepatic insulin signaling with dyslipidemia. Cell Metab 2012;15:65-74.

14. Fang S, Suh JM, Reilly SM, Yu E, Osborn O, Lackey D, et al. Intestinal FXR agonism promotes adipose tissue browning and reduces obesity and insulin resistance. Nat Med 2015;21:159-65.

15. Sinai CJ, Tohkin M, Miyata M, Ward JM, Lambert G, Gonzalez FJ. Targeted disruption of the nuclear receptor FXR/BAR impairs bile acid and lipid homeostasis. Cell 2000;102:731-44.

16. Poole DP, Godfrey C, Cattaruzza F, Cottrell GS, Kirkland JG, Pelayo JC, et al. Expression and function of the bile acid receptor GP-BAR1 (TGR5) in the murine enteric nervous system. Neurogastroenterol Motil 2010;22:814-25.

17. Alemi F, Poole DP, Chiu J, Schoonjans K, Cattaruzza F, Grider JR, et al. The receptor TGR5 mediates the prokinetic actions of intestinal bile acids and is required for normal defecation in mice. Gastroenterology 2013;144:145-54.

18. Katsuma S, Hirasawa A, Tsujimoto G. Bile acids promote glucagon-like peptide-1 secretion through TGR5 in a murine enteroendocrine cell line STC-1. Biochem Biophys Res Commun 2005;329:386-90.

19. Holst JJ. The physiology of glucagon-like peptide 1. Physiol Rev 2007;87: 1409-39.

20. Adrian TE, Gariballa S, Parekh KA, Thomas SA, Saadi H, Al Kaabi J, et al. Rectal taurocholate increases $\mathrm{L}$ cell and insulin secretion, and decreases blood glucose and food intake in obese type 2 diabetic volunteers. Diabetologia 2012; 55:2343-7.

21. Osto M, Abegg K, Bueter M, le Roux CW, Cani PD, Lutz TA. Roux-en$\mathrm{Y}$ gastric bypass surgery in rats alters gut microbiota profile along the intestine. Physiol Behav 2013;119:92-6.

22. Taylor R. Banting Memorial lecture 2012: reversing the twin cycles of type 2 diabetes. Diabet Med 2013;30:267-75.

23. Mingrone G, Panunzi S, De Gaetano A, Guidone C, Iaconelli A, Leccesi $\mathrm{L}$, et al. Bariatric surgery versus conventional medical therapy for type 
2 diabetes. N Engl J Med 2012; 26;366:1577-85.

24. Dicker D, Yahalom R, Comaneshter DS, Vinker S, Long-Term. Outcomes of Three Types of Bariatric Surgery on Obesity and Type 2 Diabetes Control and Remission. Obes Surg 2015 Dec 30. [Epub ahead of print]

25. Inge TH, Courcoulas AP, Jenkins TM, Michalsky MP, Helmrath MA, Brandt ML, et al. Teen-LABS ConsortiumWeight Loss and Health Status 3 Years after Bariatric Surgery in Adolescents. N Engl J Med 2016;374:11323.

26. Belgaumkar AP, Vincent RP, Carswell KA, Hughes RD, Alaghband-Zadeh J, Mitry RR, et al. Changes in Bile Acid Profile After Laparoscopic Sleeve Gastrectomy are Associated with Improvements in Metabolic Profile and Fatty Liver Disease. Obes Surg 2016;26:1195-202.

27. Albaugh VL, Flynn CR, Cai S, Xiao Y, Tamboli RA, Abumrad NN. Early Increases in Bile Acids Post Roux-en-Y Gastric Bypass Are Driven by Insulin-Sensitizing, Secondary Bile Acids. J Clin Endocrinol Metab 2015;100:E1225-33.

28. Patti ME, Houten SM, Bianco AC, Bernier R, Larsen PR, Holst JJ, Badman MK, et al. Serum bile acids are higher in humans with prior gastric bypass: potential contribution to improved glucose and lipid metabolism. Obesity 2009;17:1671-7.

29. Pournaras DJ, Glicksman C, Vincent RP, Kuganolipava S, AlaghbandZadeh J, Mahon D, et al. The role of bile after Roux-en-Y gastric bypass in promoting weight loss and improving glycaemic control. Endocrinology 2012;153:3613-9.

30. Kohli R, Setchell KD, Kirby M, Myronovych A, Ryan KK, Ibrahim SH, et al. A surgical model in male obese rats uncovers protective effects of bile acids post-bariatric surgery. Endocrinology 2013;154:2341-51.

31. Vincent RP, Omar S, Ghozlan S, Taylor DR, Cross G, Sherwood RA, et al. Higher circulating bile acid concentrations in obese patients with type 2 diabetes. Ann Clin Biochem 2013;50:360-4.

32. Jahansouz C, Xu H, Hertzel AV, Serrot FJ, Kvalheim N, Cole A, et al. Bile acids increase independently From hypocaloric restriction after bariatric surgery. Ann Surg 2015 Dec 10. [Epub ahead of print]

33. Cipriani S, Mencarelli A, Palladino G, Fiorucci S. FXR activation reverses insulin resistance and lipid abnormalities and protects against liver steatosis in Zucker (fa/fa) obese rats. J Lipid Res 2010;51:771-84.

34. Sayin SI, Wahlström A, Felin J, Jäntti S, Marschall HU, Bamberg K, et al. Gut microbiota regulates bile acid metabolism by reducing the levels of tauro-beta-muricholic acid, a naturally occurring FXR antagonist. Cell Metab 2013;17:225-35.

35. Flynn CR, Albaugh VL, Cai S, Cheung-Flynn J, Williams PE, Brucker $\mathrm{RM}$, et al. Bile diversion to the distal small intestine has comparable metabolic benefits to bariatric surgery. Nat Commun 2015;6:7715.

36. Bhutta HY, Rajpal N, White W, Freudenberg JM, Liu Y, Way J, et al. Effect of Roux-en-Y gastric bypass surgery on bile acid metabolism in normal and obese diabetic rats. PLoS One 2015;10:e0122273.

37. Kohli R, Bradley D, Setchell KD, Eagon JC, Abumrad N, Klein S. Weight loss induced by Roux-en-Y gastric bypass but not laparoscopic adjustable gastric banding increases circulating bile acids. J Clin Endocrinol Metab 2013;98:E708-12.

38. Spinelli V, Lalloyer F, Baud G, Osto E, Kouach M, Daoudi M, Vallez E, Raverdy V, Goossens JF, Descat A, Doytcheva P, Hubert T, Lutz TA, Lestavel S, Staels B, Pattou F, Tailleux A. Influence of Roux-en-Y gastric bypass on plasma bile acid profiles: a comparative study between rats, pigs and humans. Int J Obes 2016; Mar 22. [Epub ahead of print]

39. Pournaras DJ, le Roux CW. Are bile acids the new gut hormones? Lessons from weight loss surgery models. Endocrinology 2013;154:2255-6.

40. Simonen M, Dali-Youcef N, Kaminska D, Venesmaa S, Kakela P, Paakkonen $\mathrm{M}$, et al. Conjugated bile acids associate with altered rates of glucose and lipid oxidation after Roux-en-Y gastric bypass. Obes Surg 2012;22:1473-80.

41. Steinert RE, Peterli R, Keller S, Meyer-Gerspach AC, Drewe J, Peters T, et al. Bile acids and gut peptide secretion after bariatric surgery: A 1-year prospective randomized pilot trial. Obesity 2013;21:E660-8.
42. Jørgensen NB, Dirksen C, Bojsen-Møller KN, Kristiansen VB, Wulff $\mathrm{BS}$, Rainteau $\mathrm{D}$, et al. Improvements in glucose metabolism early after gastric bypass surgery are not explained by increases in total bile acids and fibroblast growth factor 19 concentrations. J Clin Endocrinol Metab 2015;100:E396-406.

43. Dutia R, Embrey M, O’Brien S, Haeusler RA, Agénor KK, Homel P, et al. Temporal changes in bile acid levels and 12a-hydroxylation after Rouxen-Y gastric bypass surgery in type 2 diabetes. Int J Obes 2015;39:806-13.

44. Prinz P, Hofmann T, Ahnis A, Elbelt U, Goebel-Stengel M, Klapp BF, et al. Plasma bile acids show a positive correlation with body mass index and are negatively associated with cognitive restraint of eating in obese patients. Front Neurosci 2015;9:199.

45. Schmidt JB, Pedersen SD, Gregersen NT, Vestergaard L, Nielsen MS, Ritz $\mathrm{C}$, et al. Effects of RYGB on energy expenditure, appetite and glycaemic control: a randomized controlled clinical trial. Int J Obes 2013; Aug 25. [Epub ahead of print]

46. Teodoro JS, Zouhar P, Flachs P, Bardova K, Janovska P, Gomes AP, et al. Enhancement of brown fat thermogenesis using chenodeoxycholic acid in mice. Int J Obes 2014;38:1027-34.

47. Zietak M, Kozak LP. Bile acids induce uncoupling protein 1-dependent thermogenesis and stimulate energy expenditure at thermoneutrality in mice. Am J Physiol Endocrinol Metab 2015; Dec 29. [Epub ahead of print]

48. Svensson PA, Olsson M, Andersson-Assarsson JC, Taube M, Pereira MJ, Froguel, et al. The TGR5 gene is expressed in human subcutaneous adipose tissue and is associated with obesity, weight loss and resting metabolic rate. Biochem Biophys Res Commun 2013; 433: 563-6.

49. Thomas C, Gioiello A, Noriega L, Strehle A, Oury J, Rizzo G, et al. TGR5-mediated bile acid sensing controls glucose homeostasis. Cell Metab 2009;10:167-77.

50. Watanabe M, Houten SM, Mataki C, Christoffolete MA, Kim BW, Sato $\mathrm{H}$, et al. Bile acids induce energy expenditure by promoting intracellular thyroid hormone activation. Nature 2006;439:484-9.

51. Damms-Machado A, Mitra S, Schollenberger AE, Kramer KM, Meile T, Königsrainer A, et al. Effects of surgical and dietary weight loss therapy for obesity on gut microbiota composition and nutrient absorption. Biomed Res Int 2015; 2015:806248.

52. Kong LC, Tap J, Aron-Wisnewsky J, Pelloux V, Basdevant A, Bouillot JL, et al. Gut microbiota after gastric bypass in human obesity: increased richness and associations of bacterial genera with adipose tissue genes. Am J Clin Nutr 2013;98:16-24.

53. Matuchansky C. Fecal microbiota after gastric bypass in human obesity. Am J Clin Nutr 2014;99:649-50.

54. Tomkin GH, Love AH. Investigation of glucose transport and 57Co vitamin B12 uptake using the everted sac technique with histological examination of the sacs after suspension in bile salts and indole. Digestion 1972;6:129-38.

55. Molloy A, Tomkin G. Altered bile in diabetic diarrhoea. Br Med J 1979;1:1084.

56. Condon JR, Robinson V, Suleman MI, Fan VS, McKeown MD. The cause and treatment of postvagotomy diarrhoea. Br J Surg 1975;62:309-12.

57. Ferslew BC, Xie G, Johnston CK, Su M, Stewart PW, Jia W, et al. Altered Bile Acid Metabolome in Patients with Nonalcoholic Steatohepatitis. Dig Dis Sci 2015;60:3318-28.

58. Lassailly G, Caiazzo R, Buob D, Pigeyre M, Verkindt H, Labreuche J, et al. Bariatric Surgery Reduces Features of Nonalcoholic Steatohepatitis in Morbidly Obese Patients. Gastroenterology 2015;149: 379-88; quiz e15-6.

59. Ferrannini E, Camastra S, Astiarraga B, Nannipieri M, Castro-Perez $\mathrm{J}$, Xie D, et al. Increased Bile Acid Synthesis and Deconjugation After Biliopancreatic Diversion. Diabetes 2015;64:3377-85.

60. Haeusler RA, Kaestner KH, Accili D. FoxOs function synergistically to promote glucose production. J Biol Chem 2010; 285:35245-8.

61. Kim-Muller JY, Zhao S, Srivastava S, Mugabo Y, Noh HL, Kim YR, et al. Metabolic inflexibility impairs insulin secretion and results in MODY-like diabetes in triple FoxO-deficient mice. Cell Metab 2014;20:593-602. 
62. Zhang K, Li L, Qi Y, Zhu X, Gan B, DePinho RA, et al. Hepatic suppression of Foxo1 and Foxo3 causes hypoglycemia and hyperlipidemia in mice. Endocrinology 2012;153:631-46.

63. Xiong X, Tao R, DePinho RA, Dong XC. Deletion of hepatic FoxO1/3/4 genes in mice significantly impacts on glucose metabolism through downregulation of gluconeogenesis and upregulation of glycolysis. PLoS One 2013;8:e74340.

64. Staels B, Kuipers F. Bile acid sequestrants and the treatment of type 2 diabetes mellitus. Drugs 2007;67:1383-92.
65. Ryan KK, Tremaroli V, Clemmensen C, Kovatcheva-Datchary P, Myronovych A, Karns R, et al. FXR is a molecular target for the effects of vertical sleeve gastrectomy. Nature 2014;509:183-8.

66. Chen Z, Meng C, Liu J, Zhang J, Kou Y, Zhang L, et al. Effects of gastric bypass on FoxO1 expression in the liver and pancreas of diabetic rats. Endocr Res 2016; 4:1-7.

How to cite this article: Tomkin GH, Daphne Owens D. Obesity diabetes and the role of bile acids in metabolism. J TransI Intern Med 2016;4: 73-80. 